\title{
Vision loss after spine surgery: review of the literature and recommendations
}

\author{
Mirza N. Baig, M.D., Ph.D., ${ }^{1}$ Martin Lubow, M.D., ${ }^{2}$ Phillip Immesoete, M.D., ${ }^{1}$ \\ Sergio D. Bergese, M.D., ${ }^{1,3}$ Elsayed-Awad Hamdy, M.D., ${ }^{3}$ ANd Ehud Mendel, M.D., ${ }^{1}$
}

${ }^{\prime}$ Department of Neurological Surgery, ${ }^{2}$ Division of Neuro-Ophthalmology, and ${ }^{3}$ Department of Anesthesiology, Ohio State University Medical Center, Columbus, Ohio

\begin{abstract}
$\checkmark$ In recent studies spinal surgery has replaced cardiac surgery as a leading cause of postoperative vision loss (POVL). Estimates of the incidence of POVL after spinal surgery range from 0.028 to $0.2 \%$, but with advances in complex spinal instrumentation and the rise in annual spinal operations, POVL may see an ominous increase in its incidence. Postoperative vision loss is an uncommon but devastating complication, with unknown origin and pathogenesis. The authors undertook a literature review and summarize the current understanding of its pathophysiology, highlight the limitations of existing knowledge, and recommend practical guidelines for avoiding this devastating outcome. (DOI: 10.3171/FOC-07/11/15)
\end{abstract}

KEY WORDS • ischemic optic neuropathy • postoperative complication vision loss

$\mathrm{T}$ HE focus of this review was to present the issue of vision loss associated with modern spinal surgery. Vision loss after spinal surgery is a unique complication of optic nerve damage resulting from ION, most often located in the posterior portion of the orbital optic nerve. This is surprising because the posterior area is rarely affected by ischemia. Such "posterior" lesions are designated PION. They have been uncommon until recently, mostly found in association with lumbar spinal surgery. We present the unique factors associated with lumbar surgeries and the patients undergoing them. Vision loss linked to ION and associated with lumbar surgery should be termed LION.

Of the many different complications resulting from spinal surgery, POVL is an uncommon but devastating morbidity, with dire consequences. It is estimated that 1 case per 100 spine surgeons annually will have a significant vision complication after surgery ${ }^{35}$ Recent studies have shown that spinal surgery is the leading cause of POVL, replacing cardiac surgery. ${ }^{6,37,42}$ Postoperative vision loss has been the

Abbreviations used in this paper: $\mathrm{AION}=$ anterior ischemic optic neuropathy; $\mathrm{CRAO}=$ central retinal artery occlusion; $\mathrm{ION}=$ ischemic optic neuropathy; LION = Lumbar ION; PION = posterior $\mathrm{ION} ; \mathrm{POVL}=$ postoperative vision loss. subject of investigation even before the era of modern spinal instrumentation and fusion techniques. ${ }^{22,41}$

Although the number of cases reported in the literature is on the rise, many questions remain regarding its origin, risk factors, pathophysiology, and prevention. We attempt to summarize the evidence in literature, highlight the limitations of existing knowledge, and recommend practical guidelines for avoiding this outcome.

\section{Summary of Literature Search Methodology}

We searched the National Library of Medicine's PubMed using key words, with subsequent review of the accompanying references and its citations. The key words included a combinations of the following: spine and postoperative visual loss, or spinal postoperative visual loss, spine and postoperative blindness, spine/spinal and posterior ischemic optic neuropathy, spine/spinal and retrobulbar optic neuropathy or spine/spinal and ischemic optic neuropathy. In our review we included articles dealing with visual complications after spinal surgery and excluded non-English language literature and duplicate results.

Using these criteria, we identified 166 cases of perioperative vision loss in 21 reports (Table 1) (Fig. 1). ${ }^{1,3,5,8-10,13,14,17 \text {, }}$ 25-32,34-36,42 
M. N. Baig et al.

TABLE 1

Summary of reported cases with postoperative vision loss after spinal surgery*

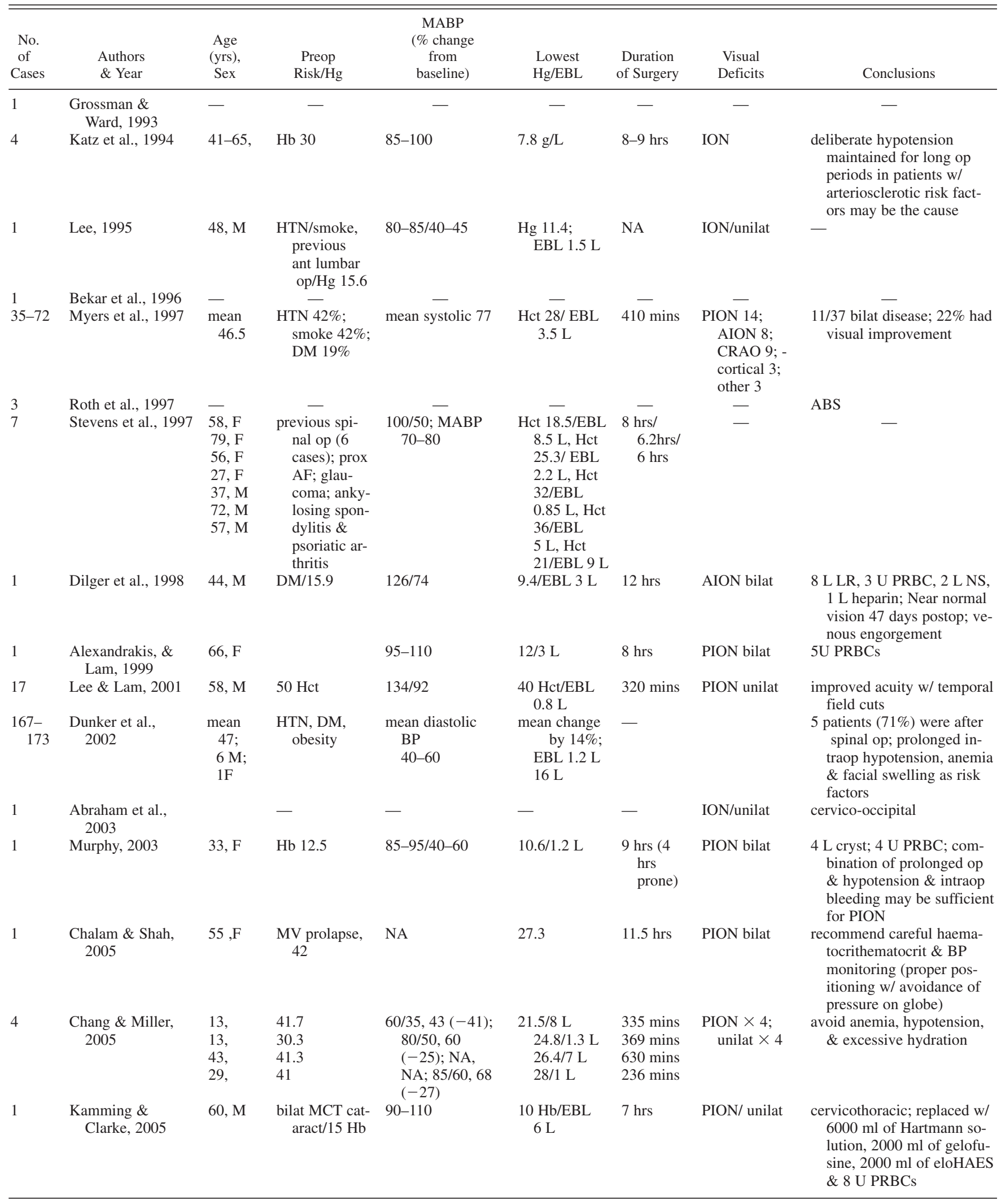


TABLE 1 (continued)

\begin{tabular}{|c|c|c|c|c|c|c|c|c|}
\hline 1 & $\begin{array}{l}\text { Katz \& Karlin, } \\
\quad 2005\end{array}$ & $12, \mathrm{~F}$ & $\begin{array}{l}\text { rt-to-lt shunt; } \\
\text { Hct } 30\end{array}$ & MABP 53-77 & $\begin{array}{l}\text { Het } 21 / \mathrm{EBL} \\
2 \mathrm{~L}\end{array}$ & $6 \mathrm{hrs}$ & CRAO, unilat & $\begin{array}{l}\text { rt-to-lt atrial shunt; } \\
\text { received } 4000 \mathrm{ml} \text { crystal- } \\
\text { loid, } 500 \mathrm{ml} \text { fresh-frozen } \\
\text { plasma, } 320 \mathrm{ml} \text { cell-saver, } \\
\text { \& } 1 \mathrm{U} \text { autologous blood }\end{array}$ \\
\hline 18 & $\begin{array}{l}\text { Chung \& Son, } \\
2006\end{array}$ & $60, \mathrm{M}$ & $13.5 \mathrm{mg} / \mathrm{dl}$ & $120 / 80-100 / 60$ & $\begin{array}{l}13.3 \mathrm{mg} / \mathrm{dL} / \\
\mathrm{NA}\end{array}$ & 295 mins & CRAO/unilat & cervical \\
\hline 19 & $\begin{array}{l}\text { Kasodekar \& } \\
\text { Chen, } 2006\end{array}$ & $62, \mathrm{M}$ & $9.8 \mathrm{~g} / \mathrm{dL}$ & NA & NA & $120 \mathrm{mins}$ & CRAO/unilat & cervical \\
\hline $\begin{array}{l}72- \\
166\end{array}$ & Lee et al., 2006 & $\begin{array}{l}\text { mean } \\
50, \\
72 \% \\
\text { male }\end{array}$ & $\begin{array}{l}\text { HTN } 41 \% \text {; } \\
\text { DM } 16 \% ; \\
\text { obesity } 53 \% \text {; } \\
\text { smoke } 46 \% ; \\
\text { previous op } \\
\text { 39\% (32/83) }\end{array}$ & $81-90$ & $\begin{array}{l}\text { Hct } 26 \text {; } \\
\text { mean EBL } \\
2 \mathrm{~L}\end{array}$ & $\begin{array}{l}94 \% \geq \\
6 \mathrm{hrs} \\
\text { mean } \\
9.8 \mathrm{hrs}\end{array}$ & $\begin{array}{l}\text { PION 56; } \\
\text { AION 19; } \\
\text { ? ION 8; } \\
\text { CRAO } 10\end{array}$ & $\begin{array}{l}\text { bilat disease in } 55 / 83 \text {; com- } \\
\text { plete visual loss in affect- } \\
\text { ed eye(s) in } 47 \text {; ION cases } \\
\text { had significantly higher } \\
\text { anesthetic duration \& } \\
\text { blood loss }\end{array}$ \\
\hline
\end{tabular}

* Abbreviations : ABS = abstract/data not available; $\mathrm{AF}=$ atrial fibrillation; ant = anterior; cryst = crystalloid; $\mathrm{DM}=$ diabetes mellitus; EBL = estimated blood loss; Hb = hemoglobin; Hct: hematocrit; HTN = hypertension; LU = liters/units; MABP = mean arterial blood pressure; MCT = medullary carcinoma of the thyroid; NA = not applicable; $\mathrm{PRBC}=$ packed red blood cells; ? = unknown; $-=$ data not available.

\section{Summary of Findings}

\section{Incidence of $P O V L$}

The most common, although not most important, eyerelated complication after spinal surgery is corneal abrasion, especial in patients treated in the prone position. ${ }^{37}$ Less frequent, but more severe complications such as POVL after nonocular surgery, have been reported after a wide variety of procedures, including coronary artery bypass surgery, craniotomy, laparotomy, radical neck dissection, hip arthroplasty, and lumbar surgery. ${ }^{6,13,22,24,28,31,37,39}$ In the field of neurosurgery, case reports in 1948 and 1954 documented POVL after spinal and cranial surgery. ${ }^{22,41}$ Review of these cases has led to improved design of headrests to avoid direct pressure on the globe.

Although the incidence of POVL may be as low as 1 in
61,000 for all nonocular surgical procedures, for spinal procedures it has been reported to be as high as 1 in 500 patients. ${ }^{37}$ The exponential increase from only 1 in 1500 patients in the late 1990s is troubling. ${ }^{18}$ Estimates for the incidence of POVL range from $0.05-4.5 \%$ for all procedures. ${ }^{40,44} \mathrm{~A}$ detailed review of spinal surgery cases, however, puts the estimates of POVL after spinal surgery between 0.028 and $0.2 \% .935,42$

Surveying 400 spine surgeons through the Scoliosis Research Society regarding POVL, Myers and associates ${ }^{35}$ identified 27 unreported complications and concluded that roughly 1 eye complication occurs for every 100 spinal procedures.

It should be noted that there has been a sharp increase in the number of surgeries performed for spinal fusion in the US. National survey data indicate that the annual number

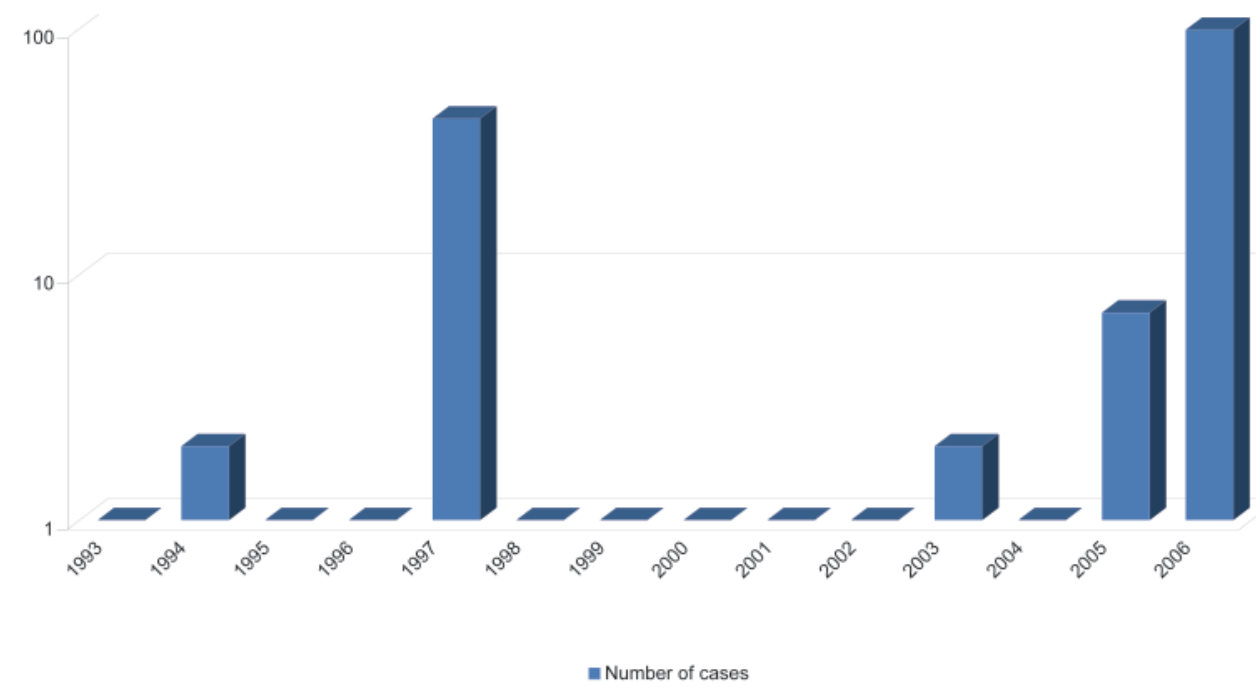

FIG. 1. Bar graph showing the number of reported cases of vision loss occurring after spinal surgery. 
M. N. Baig et al.

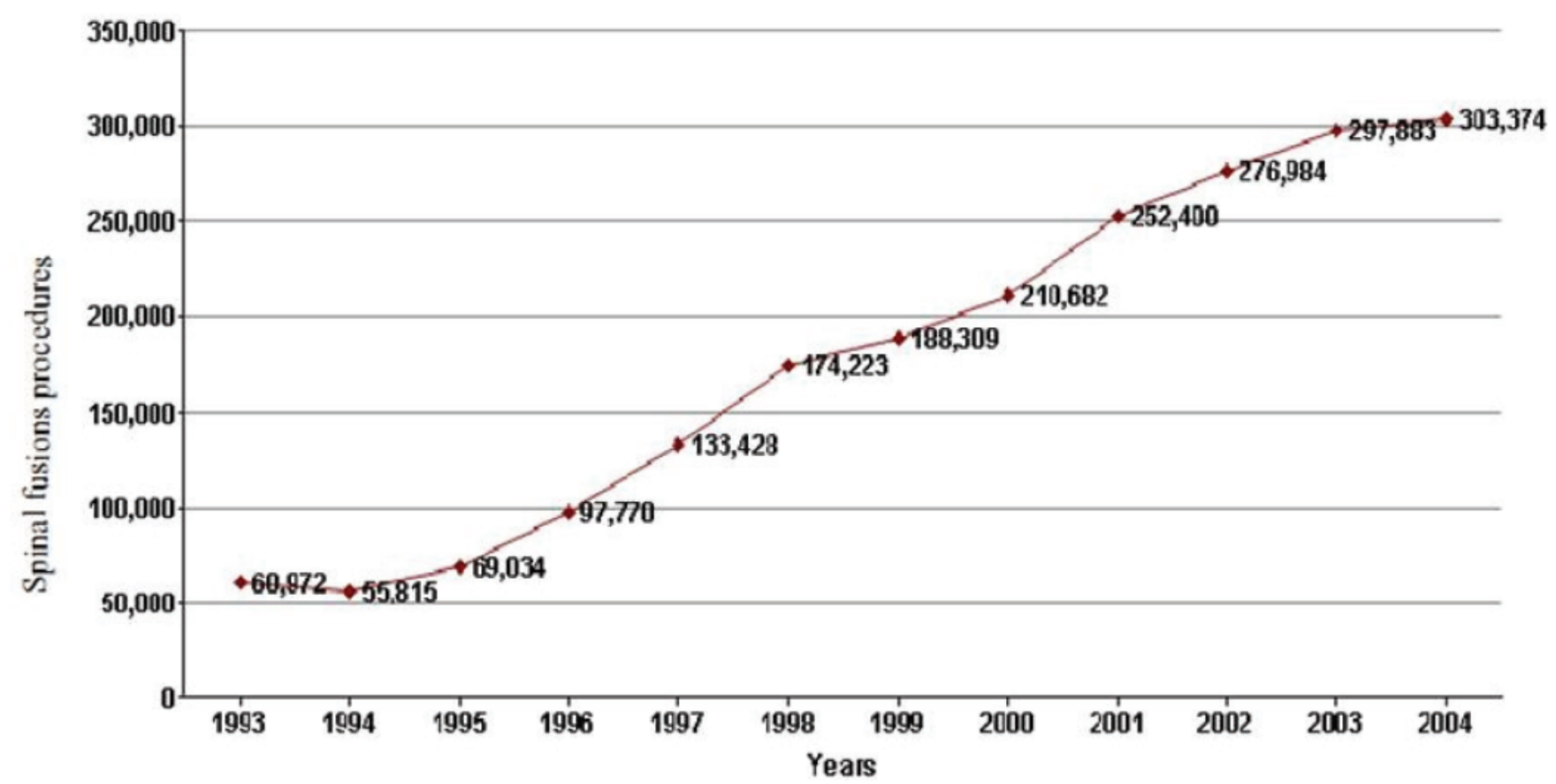

FIG. 2. Line graph demonstrating the annual number of discharges with spinal fusion operation in the US, from 1993 through 2004. Data were obtained from the Agency of Healthcare Research and Quality.

of spinal fusions rose by 500\% between 1996 and 2004, from 60,000 to 300,000 (Fig. 2). ${ }^{12,20}$ Along with advances in complex spinal instrumentation, this dramatic rise warns us of the possibility of an ominous increase in serious complications. Table 2 provides a summary of the incidence of POVL after spinal surgery estimated in 3 studies.

\section{Establishing the Diagnosis}

Vision loss after spinal surgery can be categorized into 4 groups: external ocular injury (corneal abrasion or scleral injury); cortical blindness; central retinal artery occlusion; and the important group of IONs whose unusual subtype, PION is most frequently associated with lumbar operations and thus designated by us as LION. Although we focus on the most common and most important cause of POVL, namely PION, we will also briefly discuss the other causes as well.
Corneal trauma can result in irritation, abrasion, or even laceration. Although it may be a self-limited process, such trauma increases the risk of ocular inflammation and infection. This can be prevented by the common practice of applying lubricants and taping the patient's eyes shut prior to positioning. If a corneal abrasion is found postoperatively, ophthalmic consultation is recommended.

Rarely, hemianopsia and even cortical blindness can occur secondary to major vascular insults to the visual tracts or the visual cortex. Such a neurological deficit is usually associated with a vascular or cardiac thromboembolic event or with hypoperfusion due to hypotension or cardiac dysrhythmia. As part of the neuroophthalmic workup, evaluation of postoperative vision loss will include magnetic resonance imaging to show these possible insults. Clinical findings of cortical blindness include visual field impairment with normal papillary reflexes and normal retinal examination. ${ }^{44}$ In addition to blindness, the patient may experience confusion and visual hallucinations., ${ }^{2,11}$ This will

TABLE 2

Estimates of the incidence of POVL after spinal surgery

\begin{tabular}{|c|c|c|c|c|}
\hline Authors \& Year & No. of Yrs of Study & Study Type & No. of Cases/Total Reviewed & Incidence \\
\hline Stevens et al., 1997 & 9 yrs (1985-1994) & $\begin{array}{l}\text { retrospective review of } 3 \text { in- } \\
\text { stitutions }\end{array}$ & 7 in series of 3450 spinal ops & $0.20 \%$ \\
\hline Chang \& Miller, 2005 & 20 yrs (1983-2002) & $\begin{array}{l}\text { retrospective review of } 1 \text { in- } \\
\text { stitution }\end{array}$ & $\begin{array}{l}4 \text { in series of } 14,102 \text { spinal } \\
\text { ops }\end{array}$ & $0.028 \%$ \\
\hline Myers et al., 1997 & unknown & $\begin{array}{l}\text { Scoliosis Research Society } \\
\text { Survey }\end{array}$ & $\begin{array}{l}27 \text { unreported cases through a } \\
\text { survey of } 400 \text { spine sur- } \\
\text { geons }\end{array}$ & $\begin{array}{l}1 \text { case/100 } \\
\text { spine } \\
\text { surgeons } \\
\text { yr }\end{array}$ \\
\hline
\end{tabular}




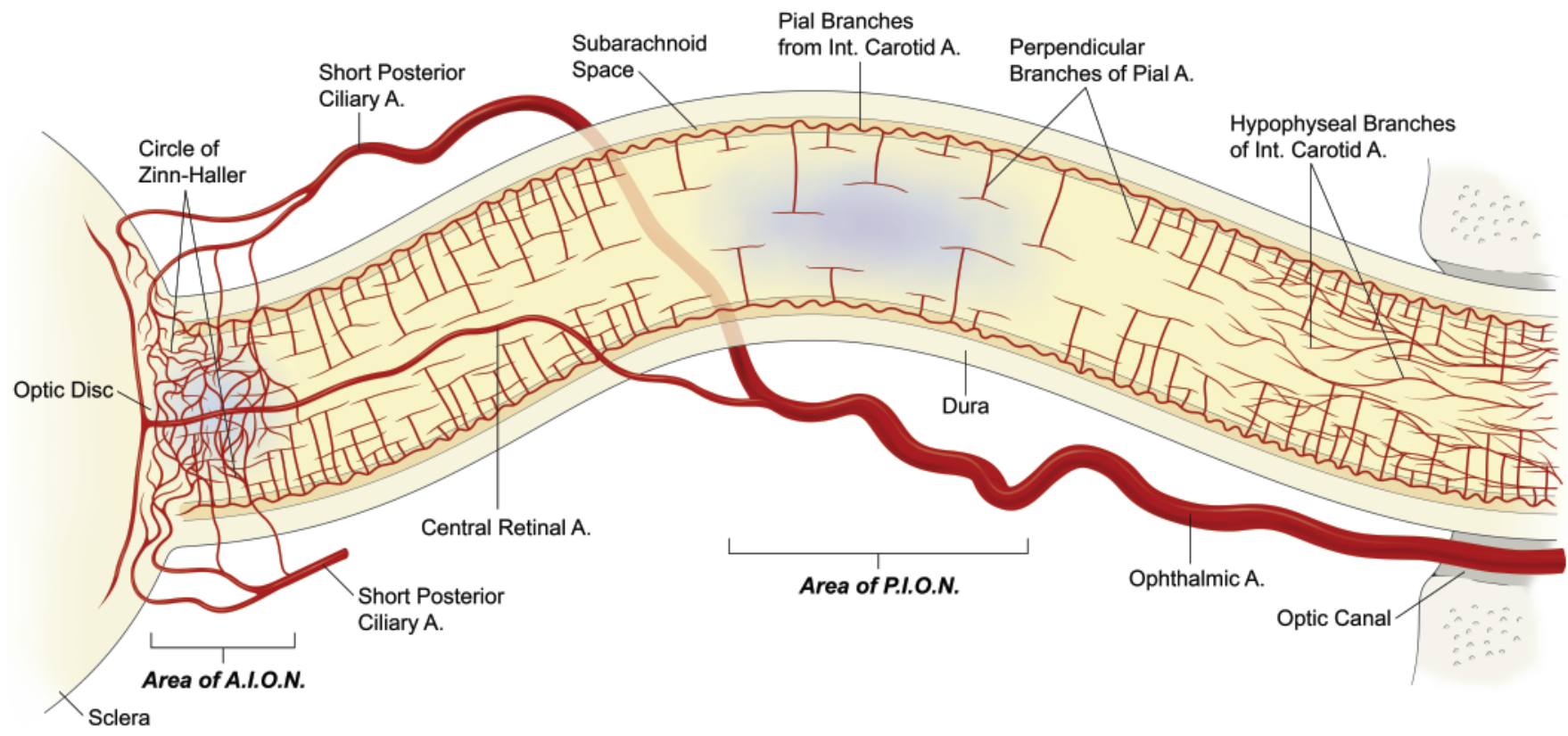

FIG. 3. Diagram of the orbital optic nerve with its vascular supply. The areas involved in the ischemic insults are highlighted in purple. The anterior optic nerve is supplied by multiple sources while only the small pial branches supply the mid-orbital optic nerve. It is the mid-orbital region of the optic nerve that is involved in PION. The pial branches are found with variable density and in an unusual perpendicular T-shaped pattern, characteristic of a low pressure system. There is low density of arteriolar and capillary supply to this mid-orbital segment compared with the canalicular or retrobulbar segments of the optic nerve. Abbreviations: A. = Artery; A.I.O.N. = Anterior Ischemic Optic Neuropathy; P.I.O.N.= Posterior Ischemic Optic Neuropathy.

often improve over hours to days with partial or even complete recovery of vision if arterial perfusion can be reestablished by treatment or collateralization. ${ }^{2}$

Central retinal artery occlusion is usually caused by direct external pressure on the globe. Common findings are unilateral vision loss with signs of external periorbital swelling or ecchymosis. Also present are a pale ischemic retina, with a pathognomonic cherry-red spot at the macula and a relative afferent pupillary defect or reduced pupillary light reflex. ${ }^{32}$ Central retinal artery occlusion is the second most common cause of blindness following prone-position spinal surgery, and it can be prevented by proper positioning of the patient in a surgical head frame. Lee and associates analyzed data obtained in 10 patients with CRAO and reported that Mayfield pins were not used in any of the cases..$^{32}$ Central retinal artery occlusion can also occur as a result of emboli and from increased intraocular pressure. ${ }^{44}$ Studies have demonstrated that patients in the prone position experience increased intraocular pressure. ${ }^{24}$ This increased intraocular pressure combined with even mild environmental insult may be sufficient in some individuals to lead to vision loss, especially in those who have undergone extended prone spinal surgeries.

The most important and the most common diagnosis in patients in whom perioperative visual deficits develop after

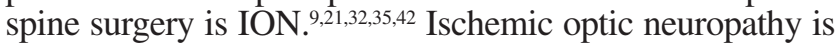
categorized as either anterior or posterior, depending on the location of the lesion in the optic nerve (Fig. 3). The AION lesion is usually located in or adjacent to the optic disc and visible on retinal examination. The parapapillary AION comprises damage caused by ischemic infarction at the an- terior watershed zone of the optic nerve. Branches of the short posterior ciliary arteries supply this region. The AION is also associated with small-vessel disease involving the small arteries of these posterior ciliary branches as seen in diabetes, hypertension, or vasculitis. ${ }^{38,44}$ It is more common in degenerative vasoocclusive diseases and often seen in patients who smoke. ${ }^{44}$ In addition, AION has been reported in association with systemic hypotension including intraoperative hypotension and severe acute hemorrhage. ${ }^{7,44}$

Posterior ischemic optic neuropathy is the most commonly reported cause of vision loss in patients in the prone position during spinal surgery. ${ }^{32,35,42}$ Key differences between AION and PION are the location of the insult and finding on the retinal examination. ${ }^{38}$ Unlike the usual AION with visible changes in the optic disc, in PION disc edema is not present. If disc edema is found several days after the insult, in a delayed fashion, then it is likely a combination of PION and delayed AION. The location in PION is thought to be in the posterior portion of the optic nerve between the optic foramen at the orbital apex and the central retinal artery's point of entry at the midportion of the orbital optic nerve. ${ }^{44}$ The posterior optic nerve may be particularly susceptible to increased venous pressure because the arterial vessels that supply the posterior optic nerve are small end vessels from the surrounding pia. ${ }^{32,35,42}$

\section{Anatomy of the Optic Nerve}

There is very little in the medical or anatomical literature that characterizes the optic nerve comprehensively. We synthesized a diagrammatic illustration of the key compo- 
M. N. Baig et al.

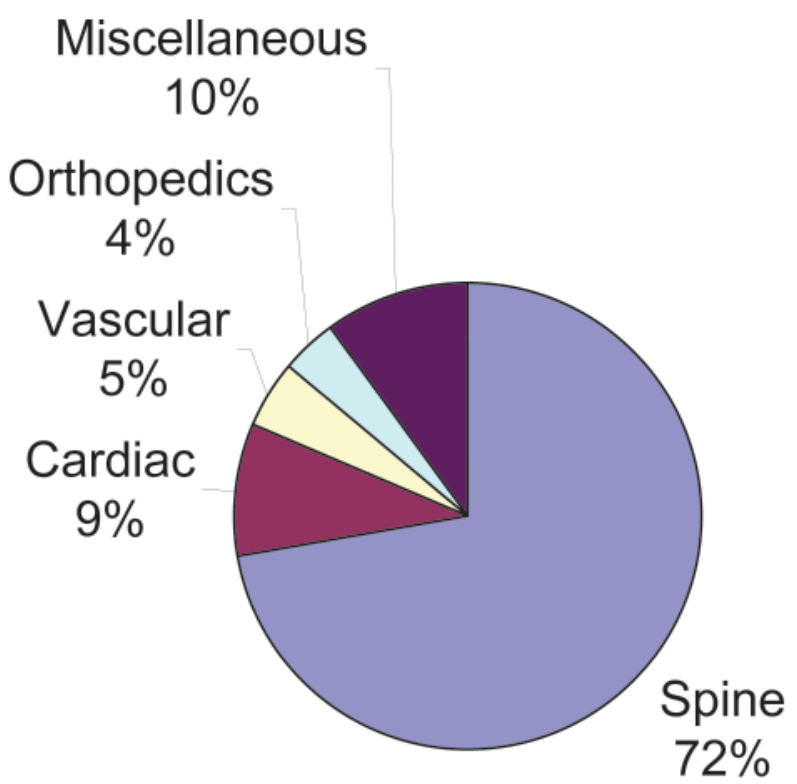

FIG. 4. Pie chart showing the distribution of cases from the American Society of Anesthesiologists POVL Registry. Data obtained from the study by Lee et al.

nents that may serve an important role in POVL. Figure 3 shows the arterial supply to the orbital optic nerve and the midorbital portion that is at risk in LION. Note that the anterior retrobulbar optic nerve is profusely supplied by multiple sources including the right and left posterior ciliary arteries and the Circle of Zinn-Haller, which itself combines ciliary, choroidal, and variable retinal arterial sources. The posterior canalicular portion of the optic nerve is supplied by multiple branches of the adjacent carotid and hypophyseal arteries. ${ }^{43}$ The critical midorbital optic nerve is supplied only by small pial branches, fed in a variable manner, from the anterior and posterior orbital arterial supply to the nerve sheath. The pial branches to the nerve structure arise in an unusual perpendicular pattern, characteristic of a low-pressure system, and extend into the nerve as arterioles and capillaries, where they branch again in a perpendicular T-shaped pattern, to run longitudinally, both anteriorly and posteriorly, at the central core level, the midperipheral level, and the superficial/peripheral level of the optic nerve. ${ }^{15,16}$ The comparative arteriolar and capillary density here, in this midorbital segment, is much less than at the canalicular or the retrobulbar segments of the nerve. ${ }^{16}$ The repeated T-shaped branchings, from the pial sheath arteries and again from the nerve penetrating arterioles to the laminar branches, are unusual and are seen in low-pressure arterial systems. ${ }^{43}$

\section{Intraoperative Factors}

Perioperative factors that have been implicated in the development of ION include intraoperative hypotension, duration of surgery, intraoperative blood loss, use of replacement fluids, and anemia. ${ }^{9,31,32,35,42}$

Errors in fluid management (usually fluid excess) were the most common cause of perioperative morbidity and mortality according to the National Confidential Inquiry in

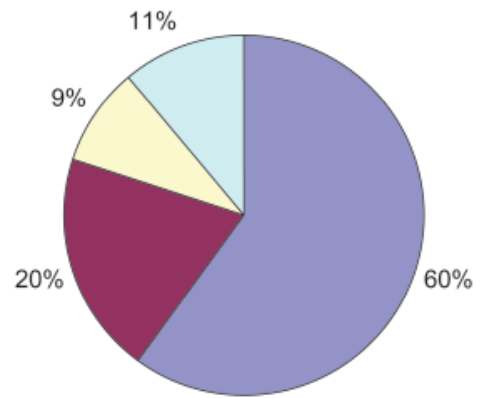

$\square$ Posterior Ischemic Optic Neuropathy

- Anterior Ischemic Optic Neuropathy

$\square$ Unknown Ischemic Optic Neuropathy

$\square$ Central Retinal Artery Occlusion

FIG. 5. Pie chart demonstrating the distribution of 93 ophthalmic lesions associated with POVL after spine surgery from the American Society of Anesthesiologists POVL Registry. Data obtained from the study by Lee et al.

England. Fluid retention after induction of ether anesthesia was first noted in 1905, and the hazards of crystalloids were first reported in $1911 .^{33}$ The transcapillary escape rate of albumin from the circulation into the interstitial space increases from 5-15\%/hour after major surgery and may take up to 10 days to return to normal. Data have shown that the human body in the supine position requires approximately 2 days to restore normal sodium and water balance after an acute crystalloid infusion. Studies involving mathematical models to analyze volume kinetics of crystalloid compared with colloid in the periorbital space in healthy volunteers are needed.

Edema compromises tissue oxygenation and produces an increase in tissue pressure in spaces like the orbital cone, which is surrounded by a nonexpandable space, thereby slowing microvascular perfusion, increasing arterial venous shunting, and reducing sympathetic drainage, all of which facilitate further edema formation. ${ }^{23}$

Removal of excess periorbital fluid can be achieved by an active sodium transport and maintenance of the gradient between the hydrostatic and colloid osmotic pressure. Active sodium transport is affected by fluid administration and the release of proinflammatory cytokines, both of which occur perioperatively. This may make a case for administration of steroid medication.

\section{Evaluation by Metaanalysis}

As a result of the low frequency of the incidence and the heterogeneity of the problem, no prospective study exists in the literature regarding origin, prevention, and treatment or animal models of eye injury that occurs in association with prone positioning during spinal surgery. However, evidence can be extrapolated from several large retrospective reviews and case reports. A metaanalysis review of the literature involving a large series of published papers has been used in an attempt to produce an accurate and widebased conclusion regarding the management of the problem at hand. ${ }^{19}$ However, the lack of well-defined studies in which investigators analyze linkage evidence prevents any quantitative analysis such as metaanalysis for this particular problem. ${ }^{4}$

Factors Associated with POVL

In 1997, Myers and colleagues ${ }^{35}$ published the only 
case-control retrospective analysis of POVL after spinal surgery, in which they surveyed the members of the Scoliosis Research Society. The authors compared data obtained in 28 patients in whom visual deficits developed after prone spine surgery and 28 controls matched for age, type of surgery, operative approach, number of spinal levels being fixed, instrumentation, and primary versus revision surgery. There were statistically significant differences between the 2 groups in the areas of intraoperative blood loss (3600 $\mathrm{ml}$ in patients with POVL and $880 \mathrm{ml}$ in controls) and duration of surgery (430 and 250 minutes, respectively). Interestingly, the hematocrit and blood pressure values were nearly identical in both groups, which implies that hematocrit and hypotension are not the main culprits in POVL. Additionally, this study suggests that duration of surgery and blood loss may have important contributory roles, but are not the only factors in the development of POVL.

The recently published American Society of Anesthesiologists Postoperative Visual Loss Registry by Lee et al. ${ }^{32}$ has shed more light on some of the factors associated with POVL. Of the 131 cases with POVL in the registry, 93 $(71 \%)$ were associated with spinal surgery (Fig. 4). Most of the spinal procedures were performed in relatively healthy patients (41\% with a history of hypertension and $16 \%$ with a history of diabetes) on an elective basis (93\% elective). Of these cases, $72 \%$ of the patients were male and $53 \%$ were obese. Most cases of POVL were attributed to ION $(89 \%)$, with most diagnosed as PION (60\% PION compared with $20 \%$ AION). The different types of vision loss are summarized in graph form in Fig. 5.

The POVL Registry data provide some important findings. They further reaffirmed the importance of the duration of surgery (94\% cases took $\geq 6$ hours) and blood loss $(82 \%$ with $>1 \mathrm{~L})$ as significant factors associated with POVL.

Interestingly, when using the CRAO group for comparison, the authors of the POVL Registry study were also able to highlight some important points..$^{32}$ As stated earlier, the evidence for cause of CRAO was direct facial-orbital compression, and not as complicated and multifactorial as for ION. The authors were able to demonstrate that the lack of use of Mayfield pins and ipsilateral periocular trauma were statistically significant findings in the CRAO group. The importance of the duration of surgery and estimated blood loss were reconfirmed and statistically significant when the ION and CRAO groups were compared.

Particularly notable was the use of replacement fluids in those patients with ION. There was a significant statistical difference in the volume of crystalloid infusion in patients with subsequent ION compared with those in the CRAO group. An average of $9.7 \mathrm{~L}$ of crystalloids were infused in cases of ION compared with $4.6 \mathrm{~L}$ in others, whereas the hematocrit value comparison was not statistically significant (26 compared with 31, respectively). Previously, these two factors had been discussed in the literature with an overemphasis on postoperative anemia and with sparse mention of the importance of overhydration. Both of these factors may be interrelated and their significance is difficult to discern. However, fluid overload has been mentioned as possibly playing a role in past case reports, and this is the first study to highlight its importance. ${ }^{9,31}$

Clearly, other factors may play a role in the development of POVL. Intrinsic factors such as coexisting disease or ocular vascular anatomy or extrinsic factors such as operative frame and type of fluid used may also have an important but yet unknown role in this disease origin.

\section{Discussion}

In summary, significant factors in POVL include excessive duration of surgery, large amount of blood loss and the excessive use of replacement fluids. Other important factors are patient positioning and severe hypotension. More research is needed on the effects of anemia, hypotension, and of the differences between colloid and crystalloid infusions.

\section{Treatment Recommendations}

Recognition of the danger of fluid overload, overhydration, extravasation of crystalloid fluids, and tissue compression due to the unusual arterial supply of the midorbital optic nerve, in its closed conelike compartment, helps the surgeon anticipate and prevent optic nerve damage. The risk of optic nerve damage increases as fluid pressure increases with prone positioning, operative time, and the kinetics of movement of intravascular fluid into extravascular tissues and spaces in the orbit; the damage is manifested postoperatively as profound lid and orbital edema.

Preoperative Recommendation 1: Risk Recognition. Preoperative consultation should include discussion of the risk and benefits of the surgical procedure, including the minimal risk of optic nerve damage resulting in blindness. Although there is a low incidence of POVL, mention of this severe complication, especially prior to complex spinal cases, would be advisable.

Preoperative Recommendation 2: Optimization. The combination of high-volume blood loss, controlled hypotension, and prolonged duration of anesthesia require vigilance on the part of the anesthesiologist. All are unusual and hazardous considerations.

Operating Room 1. Positioning: Optimal positioning for surgery would place the orbit above the level of the heart to avoid venous pooling in the orbit.

Operating Room 2. Use agents that stabilize cellular membrane and membrane transport channels. This may be a new avenue to promote fluid equilibrium by specifically targeting channels such as epithelial sodium channel. There is only empirical evidence to support this consideration.

Operating Room 3. Fluids should be controlled to limit overhydration. There is mounting evidence from the recent POVL Registry study ${ }^{32}$ and other anecdotal references that supports limiting overhydration. The key may be to optimize osmotically active fluids with colloids fluids when possible.

Operating Room 4. Rest stops should be used to elevate the patient's head. If possible the anesthesiologist can coordinate with the surgeon to change orbital position. For example, a 3-minute head elevation after every 30 minutes may help to minimize orbital edema and nerve hypoxia and thereby decrease risk and ischemia/reperfusion concerns.

Operating Room 5. Staging should be done when possible in high-risk patients. Orbital edema is the biomarker for impending orbital ischemia.

Recovery Room 1. Flat positioning should be avoided 
except as needed for hypotension. The orbit is full of fluid and needs drainage in a timely fashion.

Operating Room 2. Monitor and record blood pressure, orbital edema tension (lids tight and immovable, movable, moving), pupils (round versus elliptical, reactive versus non-reactive, equal versus unequal), vision at specified time (none, light, shadows, counts fingers, reads print card). The natural history of this syndrome is incomplete. There is realistic concern that initial insult may be followed by recurrent, milder injury. We must be vigilant in documenting possible alternative mechanism/factors.

\section{Conclusions}

The radical increase in spinal surgeries performed in the US and the developed world and the significant relationship between spinal surgery and postoperative vision loss underscore the need for further research on this topic. We advocate better funding for basic science research and establishment of a standardized experimental animal model for individual examination of each factor. Advances in bench-side research are necessary to determine the underlying causes and means to prevent POVL.

\section{References}

1. Abraham M, Sakhuja, N, Sinha, S, Rastogi, S: Unilateral visual loss after cervical spine surgery. J Neurosurg Anesthesiol 15: 319-322, 2003

2. Aldrich M, Alessi AG, Beck RW, Gilman S: Cortical blindness: etiology, diagnosis, and prognosis. Ann Neurol 21:149-158, 1987

3. Alexandrakis G, Lam BL: Bilateral posterior ischemic optic neuropathy after spinal surgery. Am J Ophthalmol 127:354-355, 1999

4. American Society of Anesthesiologists Task Force on Perioperative Blindness: Practice advisory for perioperative visual loss associated with spine surgery: a report by the American Society of Anesthesiologists Task Force on Perioperative Blindness. Anesthesiology 104:1319-1328, 2006

5. Bekar A, Türeyen K, Aksoy K: Unilateral blindness due to patient positioning during cervical syringomyelia surgery: unilateral blindness after prone position. J Neurosurg Anesthesiol 8: 227-229, 1996

6. Breuer A, Furlan AJ, Hanson MR, Lederman RJ, Loop FD, Cosgrove DM, et al: Central nervous system complications of coronary artery bypass graft surgery: prospective analysis of 421 patients. Stroke 14:682-687, 1983

7. Brown R, Schauble JF, Miller NR: Anemia and hypotension as contributors to perioperative loss of vision. Anesthesiology 80: 222-226, 1994

8. Chalam KV, Shah VA: Severe bilateral posterior ischemic optic neuropathy as a complication of spinal surgery. Eye 19:367368,2005

9. Chang SH, Miller NR: The incidence of vision loss due to perioperative ischemic optic neuropathy associated with spine surgery: the Johns Hopkins Hospital Experience. Spine 30:12991302,2005

10. Chung M, Son JH: Visual loss in one eye after spinal surgery. Korean J Ophthalmol 20:139-142, 2006

11. Dalman JE, Verhagen WI, Huygen PL: Cortical blindness. Clin Neurol Neurosurg 99:282-286, 1997

12. Deyo RA, Nachemson A, Mirza SK: Spinal-fusion surgery-the case for restraint. N Engl J Med 350:722-726, 2004
13. Dilger JA, Tetzlaff JE, Bell GR, Kosmorsky GS, Agnor RC, O'Hara JF Jr: Ischaemic optic neuropathy after spinal fusion. Can J Anaesth 45:63-66, 1998

14. Dunker S, Hsu HY, Sebag J, Sadun AA: Perioperative risk factors for posterior ischemic optic neuropathy. J Am Coll Surg 194:705-710, 2002

15. Fryczkowski AW: [Microcirculation in the optic nerve. I.] Klin Oczna 85:97-100, 1983 (Pol)

16. Fryczkowski AW: [Microcirculation in the optic nerve. II.] Klin Oczna 89:277-282, 1987 (Pol)

17. Grossman W, Ward WT: Central Retinal Artery occlusion after scoliosis surgery in a horseshoe headrest. Case report and literature review. Spine 18:1226-1228, 1993

18. Haddad A: Anatomy of a defense: could PION have been foreseen? Anesth Malpractice Prevention 6:73-80, 2001

19. Haines SJ: Evidence-based neurosurgery. Neurosurgery 52:3647, 2003

20. Healthcare Cost and Utilization Project, HCUPnet: H-CUPnet. Rockville, MD: Agency for Healthcare Research and Quality, 2007 (http: //hcupnet.ahrq.gov/) [Accessed 22 October 2007]

21. Ho VT, Newman NJ, Song S, Ksiazek S, Roth S: Ischemic optic neuropathy following spine surgery. J Neurosurg Anesthesiol 17:38-44, 2005

22. Hollenhorst RW, Svein, HJ, Benoit CF: Unilateral blindness occurring during anesthesia for neurosurgical operations. AMA Arch Ophthalmol 52:819-830, 1954

23. Holte K, Sharrock NE, Kehlet H: Pathophysiology and clinical implications of perioperative fluid excess. Br J Anaesth 89: 622-632, 2002

24. Jaben S, Glaser JS, Daily M: Ischemic optic neuropathy following general surgical procedures. J Clin Neuroophthalmol 3: 239-244, 1983

25. Kamming D, Clarke S: Postoperative visual loss following prone spinal surgery. Br J Anaesth 95:257-260, 2005

26. Kasodekar V, Chen JL: Monocular blindness: a complication of intraoperative positioning in posterior cervical spine surgery. Singapore Med J 47:631-633, 2006

27. Katz D, Karlin LI: Visual field defect after posterior spine fusion. Spine 30:E83-E85, 2005

28. Katz DM, Trobe JD, Cornblath WT, Kline LB: Ischemic optic neuropathy after lumbar spine surgery. Arch Ophthalmol 112: 925-931, 1994

29. Kim J, Hills WL, Rizzo JF, Egan RA, Lessell S: Ischemic optic neuropathy following spine surgery in a 16-year-old patient and a ten-year-old patient. J Neuroophthalmol 26:30-33, 2006

30. Lee A: Ischemic optic neuropathy following lumbar spine surgery. Case report. J Neurosurg 83:348-399, 1995

31. Lee LA, Lam AM: Unilateral blindness after prone lumbar spine surgery. Anesthesiology 95:793-795, 2001

32. Lee LA, Roth S, Posner KL, Cheney FW, Caplan RA, Newman NJ, et al: The American Society of Anesthesiologists Postoperative Visual Loss Registry: analysis of 93 spine surgery cases with postoperative visual loss. Anesthesiology 105:652-659, 2006

33. Lobo DN, Macafee, DA, Allison SP: How perioperative fluid balance influences postoperative outcomes. Best Practice Res Clin Anaesthesiol 20:439-455, 2006

34. Murphy M: Bilateral posterior ischemic optic neuropathy after lumbar spine surgery. Ophthalmology 110:1454-1457, 2003

35. Myers MA, Hamilton SR, Bogosian AJ, Smith CH, Wagner TA: Visual loss as a complication of spine surgery. A review of 37 cases. Spine 22:1325-1329, 1997

36. Roth $S$, Nuñez, R, Schreider, BD: Unexplained visual loss after lumbar spinal fusion. J Neurosurg Anesthesiol 9:346-348, 1997

37. Roth S, Thisted RA, Erickson JP, Black S, Schreider BD: Eye injuries after nonocular surgery. A study of 60,965 anesthetics from 1988 to 1992. Anesthesiology 85:1020-1027, 1996

38. Sadda SR, Nee M, Miller NR, Biousse V, Newman NJ, Kouzis 


\section{Lumbar ischemic optic neuropathy}

A: Clinical spectrum of posterior ischemic optic neuropathy. Am J Ophthalmol 132:743-750, 2001

39. Schobel GA, Schmidbauer M, Millesi W, Undt G: Posterior ischemic optic neuropathy following bilateral radical neck dissection. Int J Oral Maxillofac Surg 24:283-287, 1995

40. Shaw PJ, Bates D, Cartlidge NE, Heaviside D, French JM, Julian DG, et al: Neuro-ophthalmological complications of coronary artery bypass graft surgery. Acta Neurol Scand 76:1-7, 1987

41. Slocum H, O’Neil KC, Allen CR: Neurovascular complications from malposition on the operating table. Surg Gynecol Obstet 86:729-734, 1948

42. Stevens W, Glazer PA, Kelley SD, Lietman TM, Bradford DS: Ophthalmic complications after spinal surgery. Spine 22: 1319-1324, 1997
43. van Overbeek J, Sekhar L: Microanatomy of the blood supply to the optic nerve. Orbit 22:81-88, 2003

44. Williams EL, Hart WM Jr, Tempelhoff R: Postoperative ischemic optic neuropathy. Anesth Analg 80:1018-1029, 1995

Manuscript submitted August 16, 2007.

Accepted September 14, 2007.

Address correspondence to: Ehud Mendel, M.D., Department of Neurological Surgery, Ohio State University Medical Center, Columbus, Ohio. email: ehud.mendel@osumc.edu. 